\title{
Q ualidade tecnológica da cana-de-açúcar sob adubação com torta de filtro enriquecida com fosfato solúvel
}

\author{
Diego H. Santos ${ }^{1}$, Marcelo de A. Silva ${ }^{2}$, Carlos S. Tiritan ${ }^{3}$, José S. S. Foloni ${ }^{4} \&$ Fábio R. Echer ${ }^{1}$ \\ RESU MO \\ O trabalho teve por objetivo avaliar o rendimento de açúcar em função da adubação com torta de filtro \\ enriquecida com fontes solúveis de fósforo. 0 experimento foi conduzido a campo, em Presidente \\ Prudente, SP. Adotou-se o delineamento experimental em blocos completos ao acaso, no esquema \\ fatorial $5 \times 4$, em que o primeiro fator constou de níveis de torta de filtro $\left(0 ; 0,5 ; 1,0 ; 2,0\right.$ e 4,0 t ha $\left.^{-1}\right)$ e 0 \\ segundo de níveis de fósforo $\left(0,50,100,200 \mathrm{~kg} \mathrm{ha}^{-1}\right.$ de $\left.\mathrm{P}_{2} \mathrm{O}_{5}\right)$, com 4 repetições, totalizando 80 parcelas. \\ Os resultados indicaram que o fósforo aplicado no sulco de plantio melhora a qualidade da matéria- \\ prima da cana-de-açúcar, por meio do aumento nos teores de sólidos solúveis, de açúcares redutores \\ totais e de sacarose nos colmos; o fósforo também aumenta a produtividade de açúcar. A torta de filtro \\ aplicada no sulco de plantio da cana-de-açúcar tem potencial para substituir parcialmente a adubação \\ química fosfatada visando à melhoria na qualidade e na produtividade de açúcar. A melhor combinação \\ foi torta de filtro na dose entre 2,6 e 2,7 t ha-1 associada a 160 e $190 \mathrm{~kg} \mathrm{ha}^{-1}$ de $\mathrm{P}_{2} \mathrm{O}_{5}$, para obter melhores \\ respostas visando ao teor de sólidos solúveis e à produtividade de açúcar.
}

Palavras-chave: Saccharum spp., adubação organomineral, superfosfato triplo, produtividade de açúcar

\section{Technological quality of sugarcane under fertilization with filter cake enriched with soluble phosphate}

\begin{abstract}
The study had the objective to evaluate the effect of the fertilization with filter cake enriched with soluble phosphate on the sugar yield. The experiment carried at Presidente Prudente-SP, used a randomized complete block design, in the factorial scheme $5 \times 4$, where the first factor consisted of doses of filter cake $\left(0 ; 0.5 ; 1.0 ; 2.0\right.$ and $\left.4.0 \mathrm{tha}^{-1}\right)$ and the second, doses of phosphorus fertilizer $\left(0,50,100,200 \mathrm{~kg} \mathrm{ha}^{-1}\right.$ of $\mathrm{P}_{2} \mathrm{O}_{5}$ ), with 4 replicates, totaling 80 plots. The results indicated that phosphorus applied in planting furrows improves the quality of sugarcane raw matter by increasing the levels of soluble solids, total reducing sugars and sucrose in the stalks. The phosphorus also increases the productivity of sugar. The filter cake applied in planting furrow has the potential to partially replace the chemical fertilization with phosphate aiming to improve the quality and the productivity of sugar. The best combination was filter cake at dose between 2.6 and $2.7 \mathrm{t} \mathrm{ha}^{-1}$ combined with dose between 160 and $190 \mathrm{~kg} \mathrm{P}_{2} \mathrm{O}_{5} \mathrm{ha}^{-1}$ for obtaining best response of soluble solids and productivity of sugar.
\end{abstract}

Key words: Saccharum spp., organic-mineral fertilizers, triple superphosphate, productivity of sugar

\footnotetext{
${ }^{1}$ D outorando em Agricultura, FCA/U NESP. CP 237, CEP 18603-970, Botucatu, SP. Fone: (14) 3811-7161. E-mail: diego@fca.unesp.br ${ }^{2}$ APTA, Polo Centro-0 este, CP 66, CEP 17201-970, Jaú, SP. Fone: (14) 3621-3439. E-mail: marcelosilva@apta.sp.gov.br. Pesquisador em Produtividade do CNPq

3 U N OESTE, Rodovia Raposo Tavares, km 572, CEP 19067-175, Presidente Prudente, SP. Fone: (18) 3229-2039. E-mail: tiritan@unoeste.br ${ }^{4}$ IAPAR, CP 481, CEP 86047-902, Londrina, PR. Fone: (43) 3376-2144. E-mail: sfoloni@iapar.br
} 


\section{INTRODUÇÃO}

A cana-de-açúcar (Saccharum spp.) apresenta potencial geneticamente favorável para acúmulo de açúcares, especialmente na forma de sacarose. Sob condições ideais de cultivo este potencial é otimizado, resultado do pleno desenvolvimento das plantas. Ao final do ciclo vegetativo ocorre a maturação, quando o acúmulo de sacarose é maximizado nas plantas cultivadas.

O fósforo é considerado um elemento essencial para as plantas e se encontra em baixa quantidade nos solos brasileiros (Bastos et al., 2008). Os principais fatores que afetam a disponibilidade de $\mathrm{P}$ no solo são o teor de matéria orgânica, o teor e o tipo de argila, a capacidade de troca de cátions, o poder tampão, os teores de cálcio, ferro e alumínio e a umidade interferindo, consequentemente, na sua absorção pelas plantas (Korndörfer \& Melo, 2009). Esta condição proporciona redução na saturação por bases, com aumento gradual na retenção de ânions, como o fosfato, o sulfato e o molibdato, entre outros (Benedito et al., 2010). Em decorrência disto, os solos mudam gradualmente de fonte para dreno de fósforo inorgânico (Novais \& Smyth, 1999).

Na cana-de-açúcar o fósforo assume grande importância no enraizamento e no perfilhamento e, portanto, na produtividade final e no rendimento de açúcar (Santos, 2009). A deficiência de fósforo também é problemática pois, segundo Mahadevaiah et al. (2007), reduz a absorção de nitrogênio e dificulta a clarificação do caldo durante a fabricação do açúcar, elevando o custo de fabricação em virtude da necessidade de adição de fosfatos solúveis para atingir o teor ideal de $\mathrm{P}_{2} \mathrm{O}_{5}$, fundamental para uma clarificação eficiente.

Além dos benefícios no campo, uma boa adubação fosfatada também é de grande importância na qualidade da cana-deaçúcar, influenciando a porcentagem aparente de sacarose contida no caldo da cana (pol\%) e pureza de caldo (Simões Neto et al., 2009). A qualidade da matéria-prima é definida como o conjunto de características que a cana-de-açúcar deve apresentar, atendendo às exigências da indústria, por ocasião do processamento, em especial o teor de sacarose e a fibra industrial (Moura et al., 2005).

De acordo com Raij et al. (1997), a recomendação de adubação fosfatada no plantio da cana-de-açúcar varia de 60 a $120 \mathrm{~kg} \mathrm{ha}^{-1}$ de $\mathrm{P}_{2} \mathrm{O}_{5}$, sendo que a dose a ser aplicada está em função do $\mathrm{K}$ trocável e do $\mathrm{P}$ em resina, obtidos na análise de solo. Para aumentar a eficiência da adubação fosfatada em lavouras de cana-de-açúcar com a consequente redução das doses empregadas, principalmente em áreas que vêm sendo cultivadas com a gramínea por um longo período, Bittencourt et al. (2006) recomendam utilizar um carregador orgânico, como a torta de filtro, para proteger o fósforo da fixação, elevando a produtividade e o rendimento de açúcar por hectare.

A torta de filtro é um resíduo composto da mistura de bagaço moído e lodo da decantação, proveniente do processo de tratamento do caldo. Nunes Júnior (2008) relata que a torta de filtro sai dos filtros rotativos após extração da sacarose residual da borra com 75 a $80 \%$ de umidade e é um excelente produto orgânico para a recuperação de solos exauridos ou de baixa fertilidade. Sua composição química média apresenta altos teores de matéria orgânica e fósforo, sendo também rica em nitrogênio e cálcio, além de teores consideráveis de potássio, magnésio e micronutrientes.

O fósforo existente na torta de filtro é orgânico e sua liberação, tal como, também, do nitrogênio, se dá gradativamente por mineralização e por ataque de microorganismos no solo. O cálcio que aparece em grande quantidade é resultado da chamada caleação do caldo durante o processo de tratamento para a fabricação do açúcar; já o fósforo provém da adição de produtos auxiliares de floculação das impurezas do caldo.

Segundo Korndörfer \& Anderson (1997), a torta de filtro promove alterações significativas nos atributos químicos do solo, tais como aumento na disponibilidade de fósforo, cálcio e nitrogênio, aumento nos teores de carbono orgânico e capacidade de troca de cátions e, ainda, diminuição nos teores de alumínio trocáveis.

Muitas são as informações relativas ao valor da torta de filtro na nutrição da cana-de -açúcar, com aumento substancial na produção. Segundo Penso et al. (1982), uma das formas para seu aproveitamento é a possibilidade de aplicá-la na agricultura, misturada com fosfatos naturais, uma vez que a torta de filtro teria a capacidade de melhorar a solubilidade desses compostos, disponibilizando mais rapidamente o fósforo, comparado com a sua aplicação sem a torta.

Em virtude das fontes de fósforo possuírem baixa eficiência em solos tropicais, a hipótese do trabalho é verificar se a mistura da torta de filtro com a fonte de fósforo irá melhorar o aproveitamento do fósforo, ou seja, utilizar a torta de filtro como carregador orgânico para proteger o fósforo da fixação melhorando, desta forma, a disponibilidade deste nutriente às plantas, e verificar se o resíduo da indústria do açúcar tem potencial de substituir a fonte mineral de fósforo no plantio da cana-de-açúcar.

Neste contexto, realizou-se o presente trabalho com o objetivo de avaliar a qualidade do caldo e a produtividade de açúcar em função da adubação no plantio da cana-de-açúcar com diferentes doses de torta de filtro enriquecida com diferentes doses de uma fonte solúvel de fósforo.

\section{Material e MÉTOdos}

O experimento foi desenvolvido em área experimental da Universidade do Oeste Paulista, localizada nas coordenadas geográficas $51^{\circ} 26^{\prime} 00^{\prime \prime}$ de longitude, $22^{\circ} 07^{\prime} 30^{\prime \prime}$ de latitude e 433 m de altitude, no município de Presidente Prudente, SP. O clima da região, segundo a classificação de Köppen, é do tipo Cwa, com estação chuvosa e quente bem definida entre os meses de setembro a março e inverno seco com temperaturas amenas entre os meses de abril a setembro. O solo da área experimental foi caracterizado, segundo EMBRAPA (1999), como Argissolo Vermelho distroférrico, com relevo suave ondulado e boa drenagem. Amostras de solo foram coletadas para caracterização de atributos químicos (Raij et al., 2001) e físicos (EMBRAPA, 1997), na camada $0-20 \mathrm{~cm}$, obtendo-se os seguintes resultados: $\mathrm{pH}\left(\mathrm{CaCl}_{2} 1 \mathrm{~mol} \mathrm{~L}^{-1}\right) 5,9 ; 18 \mathrm{~g} \mathrm{dm}^{-3} \mathrm{de}$ $\mathrm{MO} ; 16 \mathrm{mg} \mathrm{dm}^{-3} \mathrm{deP}_{\text {resina }} ; 27 \mathrm{mmol}_{\mathrm{c}} \mathrm{dm}^{-3} \mathrm{de} \mathrm{H}+\mathrm{Al} ; 1,2 \mathrm{mmol}_{\mathrm{c}} \mathrm{dm}^{-3}$ 


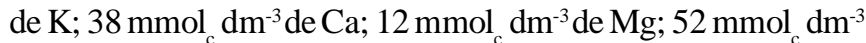
de SB; $69 \mathrm{mmol} \mathrm{dm}^{-3} \mathrm{de}$ CTC; 74\% de saturação por bases (V); $740 \mathrm{~g} \mathrm{~kg}^{-1}$ de areia; $80 \mathrm{~g} \mathrm{~kg}^{-1}$ de silte e $180 \mathrm{~g} \mathrm{~kg}^{-1}$ de argila.

A cultivar de cana-de-açúcar utilizada no experimento foi a RB867515, em função da recomendação regional. A torta de filtro foi obtida junto à Destilaria Alvorada do Oeste, no município de Santo Anastácio, SP. Uma amostra foi enviada ao laboratório para determinação da umidade; em seguida, a torta de filtro foi secada ao ar livre até atingir $80 \%$ de matéria seca e novamente uma amostra foi enviada ao laboratório onde se realizou a análise de fertilizante orgânico, segundo as análises de umidade realizadas pelo Laboratório de Tecidos Vegetais da Unoeste. A análise apresentou os seguintes resultados, expressos em matéria seca: $\mathrm{pH}\left(\mathrm{CaCl}_{2} 1 \mathrm{~mol} \mathrm{~L}^{-1}\right) 5,4 ; 70,7 \%$ de umidade perdida a $65^{\circ} \mathrm{C} ; 57,25 \%$ de $\mathrm{MO} ; 9,5 \mathrm{~g} \mathrm{~kg}^{-1} \mathrm{de} \mathrm{N} ; 3,3 \mathrm{~g}$ $\mathrm{kg}^{-1}$ de P; 4,6 $\mathrm{g} \mathrm{kg}^{-1}$ de K; 9, $1 \mathrm{~g} \mathrm{~kg}^{-1}$ de Ca; $2,5 \mathrm{~g} \mathrm{~kg}^{-1} \mathrm{de} \mathrm{Mg} ; 7,2$ $\mathrm{g} \mathrm{kg}^{-1} \mathrm{de} \mathrm{S} ; 124 \mathrm{mg} \mathrm{kg}^{-1}$ de Cu; $758 \mathrm{mg} \mathrm{kg}^{-1}$ de Mn; $282 \mathrm{mg} \mathrm{kg}^{-1}$ de $\mathrm{Zn}$ e $23808 \mathrm{mg} \mathrm{kg}^{-1}$ de Fe.

Realizou-se o preparo convencional do solo com aragem e gradagem antes do plantio. A adubação de plantio foi realizada de acordo com Raij et al. (1997), sendo $30 \mathrm{~kg} \mathrm{ha}^{-1}$ de N (66,7 kg $\mathrm{ha}^{-1}$ de ureia), $100 \mathrm{~kg} \mathrm{ha}^{-1}$ de $\mathrm{K}_{2} \mathrm{O}$ (166 $\mathrm{kg} \mathrm{ha}^{-1}$ de cloreto de potássio), variando apenas as doses de $\mathrm{P}_{2} \mathrm{O}_{5}$ e torta de filtro, segundo o delineamento experimental; posteriormente, realizou-se a cobertura nitrogenada com ureia, $45 \mathrm{~kg} \mathrm{ha}^{-1}$, segundo recomendação de Raij et al. (1997) e se utilizou o fertilizante fosfatado superfosfato triplo, com $45 \%$ de $\mathrm{P}_{2} \mathrm{O}_{5}$.

O plantio foi realizado de forma convencional, adotando-se o sistema de "cana-de-ano" ou cana de 12 meses. Na distribuição das mudas utilizou-se a densidade média de 15 gemas por metro de sulco. Cada parcela experimental constou de 5 linhas de 5 metros de comprimento, espaçadas $1,50 \mathrm{~m}$. Utilizou-se o delineamento experimental em blocos completos ao acaso, no esquema fatorial $5 \times 4$, sendo o primeiro fator as doses de torta de filtro $\left(0 ; 0,5 ; 1,0 ; 2,0\right.$ e $\left.4,0 \mathrm{tha}^{-1}\right)$ e o segundo as doses de fósforo $\left(0,50,100,200 \mathrm{~kg} \mathrm{ha}^{-1}\right.$ de $\left.\mathrm{P}_{2} \mathrm{O}_{5}\right)$, com 4 repetições, totalizando 80 parcelas.

Aos 360 dias após o plantio, realizou-se o corte manual para avaliação das variáveis tecnológicas, amostrando-se doze colmos seguidos em cada parcela experimental. Os feixes foram enviados ao laboratório de análise tecnológica para determinação do teor aparente de sólidos solúveis presentes no caldo (Brix\%) da cana, por refratometria; a polarização (Pol\%) da cana e a fibra\% da cana, pelo método baseado na regressão linear com o peso do bolo úmido (PBU), e os açúcares redutores totais (ART), segundo a metodologia vigente no SPCTS (Sistema de Pagamento da cana-de-açúcar, pelo Teor de Sacarose) descritas em Fernandes (2003).

Obteve-se a produtividade de açúcar (TPH) por meio do produto entre a produtividade de colmos $(\mathrm{TCH})$, conforme dados obtidos no mesmo experimento e publicados por Santos (2009) e a concentração de sacarose (pol cana) correspondente a cada parcela, dividido por 100 .

O estudo estatístico constou da análise de variância e teste t a 5\% de significância para comparar média de tratamentos. Fez-se também análise de regressão em que foram ajustadas equações lineares e quadráticas significativas até $5 \%$ de probabilidade, pelo teste $\mathrm{F}$; ainda se fez análise pela metodologia de superfície de resposta para determinar qual faixa de dose de torta de filtro e de fósforo exerce maior influência sobre as variáveis avaliadas.

\section{RESULTADOS E DISCUSSÃO}

A análise da variância indicou a significância das causas de variação relacionadas às doses de torta de filtro para as variáveis fibra\% cana, Brix\% caldo, ART\% cana, pol\% cana e TPH. Para doses de fosfato, as causas de variação significativas foram Brix\% caldo, pureza do caldo e TPH. Quanto às interações dessas causas de variação, verificou-se significância para Brix\% caldo, ART\% cana, pol\% cana e TPH (Tabela 1).

Tabela 1. Variáveis tecnológicas da cana-de-açúcar em função de doses de torta de fil tro e doses de $\mathrm{P}_{2} \mathrm{O}_{5}{ }^{1}$

\begin{tabular}{|c|c|c|c|c|c|c|}
\hline \multirow[b]{2}{*}{ Trat. } & \multicolumn{6}{|c|}{ Variáveis tecnológicas } \\
\hline & Fibra & Brix & Pureza & ART Cana & Pol Cana & \multirow{2}{*}{$\begin{array}{l}\text { TPH } \\
\text { t ha }{ }^{-1}\end{array}$} \\
\hline & \multicolumn{5}{|c|}{$\%$} & \\
\hline & \multicolumn{6}{|c|}{ Doses de torta $\left(\mathrm{t} \mathrm{ha}^{-1}\right)$} \\
\hline 0,0 & $14,90 \mathrm{C}$ & $20,48 \mathrm{c}$ & 89,31 & 17,91 b & $16,64 \mathrm{~b}$ & $19,54 \mathrm{~d}$ \\
\hline 0,5 & $14.91 \mathrm{c}$ & $21,96 b$ & 90, & 18,5 & 17,3 & $21,76 \mathrm{c}$ \\
\hline 1,0 & $14,99 \mathrm{bc}$ & $22,73 a$ & 90,67 & 18,73 & $17,42 \mathrm{a}$ & $24,06 \mathrm{~b}$ \\
\hline 2,0 & $15,04 \mathrm{~b}$ & $22,85 a$ & 90,35 & 18,92 & $17,59 a$ & $25,57 a$ \\
\hline \multirow[t]{2}{*}{4,0} & $15,14 \mathrm{a}$ & $21,67 \mathrm{~b}$ & 90,45 & $17,97 \mathrm{~b}$ & $16,70 \mathrm{~b}$ & $24,31 \mathrm{ab}$ \\
\hline & \multicolumn{6}{|c|}{ Doses de fosfato $\left(\mathrm{kg} \mathrm{ha}^{-1}\right)$} \\
\hline 0 & 14,95 & $20,25 d$ & $88,05 b$ & 18,26 & 16,90 & $19,14 \mathrm{C}$ \\
\hline 50 & 15,01 & $21,44 \mathrm{C}$ & $90,45 a$ & 18,37 & 17,06 & $22,53 \mathrm{~b}$ \\
\hline 100 & 14,99 & $22,75 \mathrm{~b}$ & $91,04 a$ & 18,53 & 17,27 & $25,01 \mathrm{a}$ \\
\hline \multirow[t]{2}{*}{200} & 15,04 & $23,30 \mathrm{a}$ & $91,13 a$ & 18,54 & 17,30 & $25,51 \mathrm{a}$ \\
\hline & \multicolumn{6}{|c|}{ Valores de $\mathrm{F}^{2}$} \\
\hline Torta (T) & $8,23^{* *}$ & $26,65^{* *}$ & $1,23^{\text {ns }}$ & $9,10^{* *}$ & $8,78^{* *}$ & $28,78^{* *}$ \\
\hline Fosfato (F) & $1,29^{\text {ns }}$ & $68,50^{* *}$ & $11,45^{* *}$ & $1,06^{\text {ns }}$ & $2,10^{\text {ns }}$ & $53,45^{* *}$ \\
\hline$T \times F$ & $1,81^{\mathrm{ns}}$ & $2,58^{* *}$ & $0,89^{\text {ns }}$ & $3,35^{* *}$ & $3,50^{* *}$ & $3,29^{* *}$ \\
\hline C.V. (\%) & 0,93 & 3,37 & 2,12 & 3,27 & 3,39 & 7,74 \\
\hline
\end{tabular}

${ }^{1}$ Médias seguidas de mesma letra não diferem pelo teste t a 0,05

** e ns, respectivamente: significante a 0,01 de probabilidade, e não significante

Para doses de torta de filtro, maior valor para fibra $\%$ cana foi encontrado para 4,0 $\mathrm{t} \mathrm{ha}^{-1}$, mas os maiores valores de Brix $\%$ caldo foram observados para as doses de 1,0 e 2,0 $\mathrm{t} \mathrm{ha}^{-1}$, enquanto para ART\% cana e pol\% cana, valores significativamente iguais foram obtidos para as doses 0,5, 1,0 e 2,0 $\mathrm{t} \mathrm{ha}^{-1}$. A dose de 2,0 $\mathrm{t}$ $\mathrm{ha}^{-1}$ proporcionou maior produtividade de açúcar (TPH). Neste sentido, Anjos et al. (2007) conseguiram substituir adubação química pela orgânica sem perdas na qualidade da matéria-prima de duas variedades de cana-de-açúcar.

Para fosfato, a dose de $200 \mathrm{~kg} \mathrm{ha}^{-1}$ resultou em maior Brix \% caldo e, para as variáveis pol\% cana e TPH, além desta dose também a de $100 \mathrm{~kg} \mathrm{ha}^{-1}$ superou significativamente as demais.

Quanto à produtividade de açúcar, por ser resultado tanto da produtividade de colmos quanto da concentração de sacarose, houve influência dos tratamentos torta de filtro e fosfato na melhoria da qualidade da matéria-prima confirmada, entre outras variáveis, pelos maiores valores para pol\% cana. Segundo Rossetto et al. (2008), o uso da torta de filtro nos canaviais eleva a produtividade da cultura e, por consequência, a produtividade 
de açúcar, por fornecer matéria orgânica, fósforo e cálcio, entre outros nutrientes. Os autores completam, ainda, que o uso mais eficiente deste resíduo é aplicá-lo no sulco de plantio, quando então o teor de água contido na torta favorece a brotação da cana e o fósforo, ao ser mineralizado, está próximo das raízes.

Segundo Meyer \& Wood (2001), a adubação fosfatada desempenha papel importante na fotossíntese, no desenvolvimento radicular, no perfilhamento e na qualidade do caldo da cana-de-açúcar para a indústria. Os autores, estudando duas variedades na África do Sul, verificaram que a adubação fosfatada em um solo altamente deficiente deste nutriente aumentou significativamente a produtividade e a qualidade da cana-de-açúcar. Kumar \& Verma (1999), trabalhando com diferentes doses de adubação fosfata no estado de Haryana, Índia, relataram aumento no teor de sacarose e nos demais parâmetros de qualidade do caldo.

O teor de sólidos solúveis presentes no caldo (Brix \%) da cana foi influenciado pela interação entre doses de torta de filtro $x$ doses de fosfato (Figura 1A). Observa-se que o aumento da dose de fosfato no sulco de plantio proporcionou aumento do Brix \% em todas as doses de torta de filtro aplicadas, porém nas menores doses 0 e $0,5 \mathrm{t} \mathrm{ha}^{-1}$ e na maior $4,0 \mathrm{t} \mathrm{ha}^{-1}$ de torta de filtro a resposta foi representada por regressão linear crescente, com significância a $1 \%$ de probabilidade. Por outro lado, os tratamentos com doses intermediárias de torta de filtro, 1,0 e 2,0 $\mathrm{t} \mathrm{ha}^{-1}$, foram afetados por doses mais elevadas de fosfato, sendo os efeitos representados por modelo quadrático positivo, com significância de 1 e 5\%, respectivamente.

Esses resultados revelam a importância do fósforo para a elevação da porcentagem de sólidos solúveis no caldo (Brix \%) da cana-de-açúcar visto que, mesmo na ausência da adubação química fosfatada, as doses de torta de filtro elevaram o Brix \% e, ao se elevar as doses de fosfato, também ocorreu incremento significativo nos sólidos solúveis (Figura 1A). Portanto, para esta variável a torta de filtro apresentou potencial para substituir parte da adubação química fosfatada e entre os tratamentos testados a dose de $2 \mathrm{t} \mathrm{ha}^{-1}$ associada a $100 \mathrm{~kg} \mathrm{ha}^{-1}$ de $\mathrm{P}_{2} \mathrm{O}_{5}$, mostrou-se a melhor interação, superando o tratamento sem torta e $200 \mathrm{~kg} \mathrm{ha}^{-1}$ de $\mathrm{P}_{2} \mathrm{O}_{5}$.

Quanto ao desdobramento da interação entre doses de torta de filtro e doses de $\mathrm{P}_{2} \mathrm{O}_{5}$ solúvel aplicados no sulco de plantio para açúcares redutores totais (ART, \% cana) (Figura 1B), todas as variáveis foram representadas por modelo quadrático mas apenas aquelas ajustadas para as doses 0 e $4 \mathrm{t} \mathrm{ha}^{-1}$ de torta de filtro, foram significativas a $1 \%$. A associação dos tratamentos induziu ao aumento e posterior diminuição do teor de ART. O tratamento constituído de $0 \mathrm{t} \mathrm{ha}^{-1}$ de torta de filtro, associado a $0 \mathrm{~kg} \mathrm{ha}^{-1}$ de $\mathrm{P}_{2} \mathrm{O}_{5}$, apresentou baixo rendimento de açúcares redutores totais; no entanto, com a elevação dos teores de $\mathrm{P}_{2} \mathrm{O}_{5}$ verificaram-se maiores teores de ART, indicando estádio mais adiantado de maturação.

O ART representa todos os açúcares da cana, na forma de açúcares invertidos, embora outras substâncias redutoras, presentes no caldo de cana, possam estar incluídas. Na planta, o desdobramento da sacarose em glicose e frutose é uma reação de duplo sentido, isto é, ocorre a inversão, assim como a combinação, durante o metabolismo da fotossíntese e respiração da planta; daí a importância do conhecimento do teor de ART,
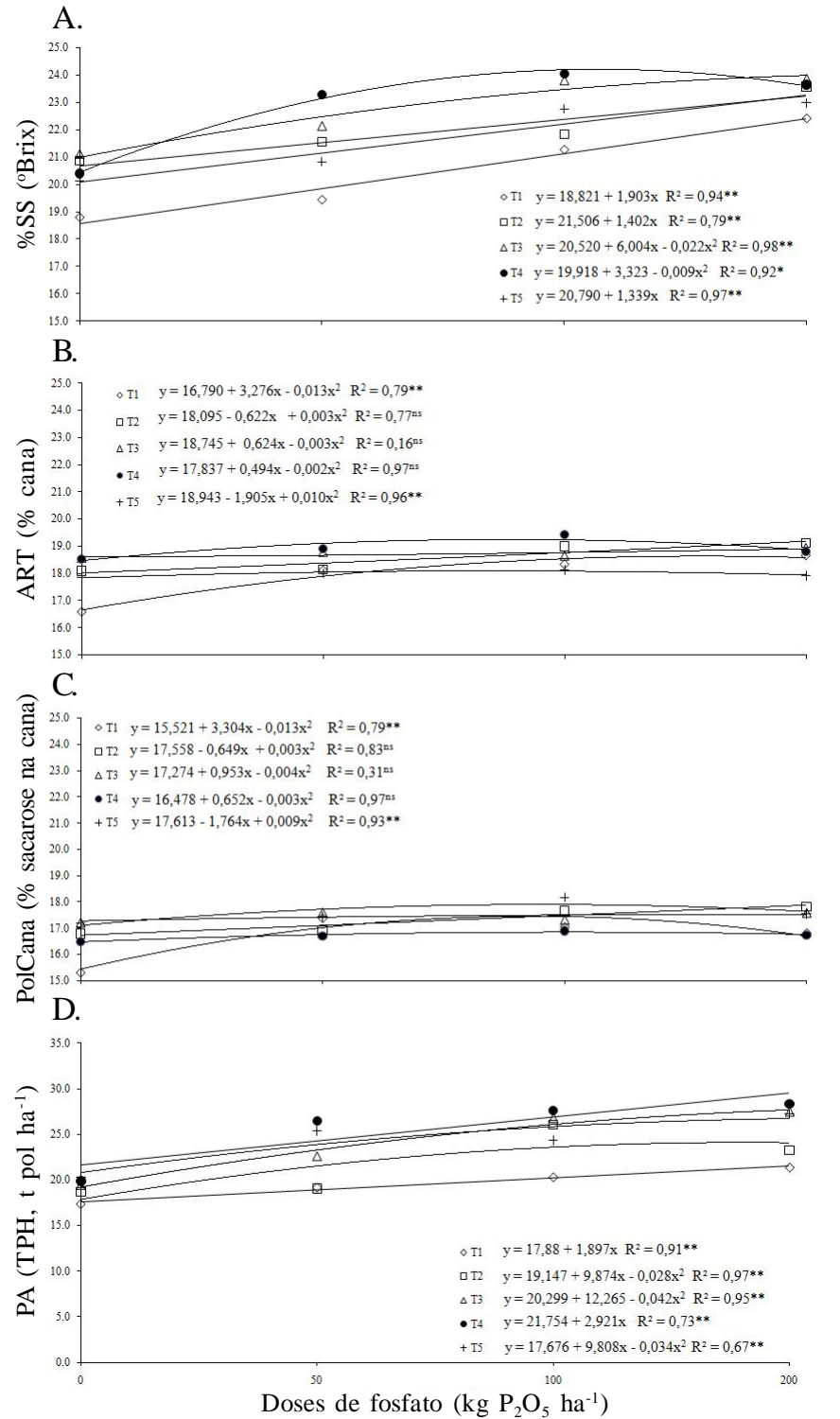

Obs. : $\mathrm{T} 1=0 ; \mathrm{T} 2=0,5 ; \mathrm{T} 3=1 ; \mathrm{T} 4=2 \mathrm{e} \mathrm{T} 5=4$ tde torta de filtro ha-1 ${ }^{-1}$ PA - produtividade de açúcar; ART - açúcares redutores totais

* e**, respectivamente: significante a $0,05,0,01$ de probabilidade

Figura 1. D esdobramento da interação doses de torta de filtro $x$ doses de fosfato da análise de variância referente aos sólidos solúveis no caldo (Bix) (A); a açúcares redutores totais na cana $(B)$; ao teor de sacarose na cana (pol \% cana) (C), e à produtividade de açúcar, em tonelada de pol por hectare (TPH) (D)

para a avaliação da qualidade da matéria-prima (Fernandes, 2003). A aplicação dos tratamentos proporcionou teores de ART superiores ao encontrado na testemunha $\left(0 \mathrm{~kg} \mathrm{ha}^{-1} \mathrm{de}_{2} \mathrm{O}_{5} \mathrm{e} 0 \mathrm{t}\right.$ de torta de filtro ha-1), o que evidencia a significância desses compostos no manejo da cana-de-açúcar, com o objetivo de se explorar o potencial de acúmulo de sacarose.

No desdobramento da interação entre doses de torta de filtro aplicadas nos sulcos de plantio e $\mathrm{P}_{2} \mathrm{O}_{5}$ solúvel para porcentagem de sacarose na cana (Pol\%) (Figura 1C), observase efeito significativo a $1 \%$ de probabilidade pelo teste $\mathrm{F}$ para as variáveis 0 e $4 \mathrm{t} \mathrm{ha}^{-1}$ de torta de filtro, enquanto as doses de $0,5,1$ e 2 t ha $^{-1}$ não apresentaram o mesmo efeito. Com ausência de torta de filtro, observa-se que o aumento das doses de 
fosfato elevou o teor de sacarose no caldo da cana-de-açúcar (Pol\%), confirmando a importância da adubação fosfatada para a qualidade do caldo de cana-de-açúcar; por sua vez, o tratamento com $4 \mathrm{t} \mathrm{ha}^{-1}$ de torta de filtro, associado a doses de fosfato, induziu ao aumento e posterior diminuição na Pol\%, demonstrado pela função quadrática, tendo-se obtido o maior valor com a interação com $100 \mathrm{~kg} \mathrm{ha}^{-1} \mathrm{de}_{2} \mathrm{O}_{5}$.

Apesar desses resultados promissores, diversos estudos mostram respostas variadas sobre a influência do fósforo na Pol\% da cana. Elamin et al. (2007) informaram que a deficiência desse elemento resulta em decréscimo significativo no acúmulo de sacarose, uma vez que a adubação fosfatada afeta diretamente a quantidade de açúcar e a pureza do caldo. Glaz et al. (2000) relataram que taxas crescentes de fósforo resultaram em aumentos lineares no rendimento de açúcar, em dois experimentos conduzidos na Flórida (EUA), enquanto no segundo experimento não houve resposta significativa à adubação fosfatada para o rendimento de açúcar, apesar da proximidade das áreas e dos solos possuírem as mesmas características, ricos em matéria orgânica; já para Lima et al. (2006) e Korndörfer \& Melo (2009) a adubação mineral fosfatada não proporcionou efeito no teor de sacarose, tal como para Pereira et al. (1995) que não observaram efeito da adubação fosfatada nas características tecnológicas da cana-de-açúcar nem entre níveis crescentes de fósforo e Pol\% da cana.

Pereira et al. (1995) relataram que fatores como clima, variedades e manejo do solo exercem influência sobre a quantidade de açúcar acumulado nos colmos da cana-de-açúcar, dificultando a avaliação do efeito de fertilizantes sobre este parâmetro. Albuquerque \& Marinho (1983) mostraram que a resposta da cana-de-açúcar à fertilização fosfatada se mostra variável, mesmo em solos deficientes em fósforo devido, provavelmente, às condições ambientais, ao manejo da cultura, à quantidade do elemento e à capacidade de fixação do elemento pelo solo.

O desdobramento de doses de fosfato versus doses de torta de filtro para a variável produtividade de açúcar (TPH) é apresentado na Figura 1D. Houve efeito significativo para todas as doses de torta de filtro estudadas. A maior dose de torta de filtro não refletiu em maior produtividade de açúcar, sendo os melhores resultados encontrados com a dose de $2 \mathrm{t} \mathrm{ha}^{-1}$; entretanto, fica evidente observar que na ausência da adubação química fosfatada se tem um ganho de produtividade de açúcar quando se aplica torta de filtro, e que a produtividade se eleva conforme se aumentam as doses de $\mathrm{P}_{2} \mathrm{O}_{5}$ solúvel. De fato, segundo Rossetto et al. (2008), o benefício da presença de radicais orgânicos na torta de filtro em decomposição pode ocupar sítios de fixação de fósforo, protegendo este nutriente da reação com os minerais de argila e óxidos de ferro e, portanto, tornando-o disponível e melhor aproveitado pela planta.

Vários são os resultados do efeito positivo da adubação fosfatada sobre a produtividade de açúcar. Kumar \& Verma (1999), constataram que níveis elevados de fósforo no solo, acima de $50 \mathrm{~kg} \mathrm{ha}^{-1}$ de $\mathrm{P}_{2} \mathrm{O}_{5}$, em razão da adubação fosfatada, podem garantir altas produtividades de açúcar. Santos et al. (2009) concluíram que a adubação fosfatada influencia positivamente o rendimento agrícola da cana-planta, sendo o superfosfato triplo a fonte de fósforo que apresentou o melhor desempenho, dentre outras estudadas. Pereira et al. (1995) também verificaram os benefícios da adubação fosfatada sobre a produtividade da cana-planta no estado da Bahia, com aumento de produtividade e teor de fósforo no caldo, justificando um programa adequado de recomendação de adubação fosfatada para maximizar o potencial agroindustrial da cultura em seu estado.

A utilização da metodologia de superfície de resposta possibilita a pesquisa de duas variáveis simultaneamente e a determinação de regiões máxima de rendimento das variáveis avaliadas. A superfície de resposta ajustou-se bem aos dados, predominando efeitos quadráticos e interação não significativa (Tabela 2).

Tabela 2. Resumo da análise por superfície de resposta de segunda ordem, em função da torta de filtro e $\mathrm{P}_{2} \mathrm{O}_{5}$ para fibra na cana, sólidos solúveis no caldo (Brix); pureza do caldo; açúcares redutores totais na cana; teor de sacarose na cana (pol cana) e produtividade de açúcar, em tonelada de pol por hectare (TPH)

\begin{tabular}{lcccccc}
\hline \multicolumn{1}{c}{ Efeitos } & Fibra & Brix & Pureza & ART & Pol Cana & TPH \\
Lineares & $\mathrm{ns}^{1}$ & $*$ & $*$ & $\mathrm{~ns}$ & $\mathrm{~ns}$ & $*$ \\
Quadráticos & $*$ & $*$ & $*$ & + & $*$ & $*$ \\
Interação & $\mathrm{ns}$ & $\mathrm{ns}$ & + & $\mathrm{ns}$ & $\mathrm{ns}$ & $\mathrm{ns}$ \\
\hline $\mathrm{R}^{2}(\%)$ & 22 & 66 & 37 & 9 & 10 & 73 \\
$\mathrm{CV}(\%)$ & 1,1 & 4,6 & 2,1 & 4,4 & 4,4 & 9,1 \\
\hline Torta & $*$ & $*$ & + & $\mathrm{ns}$ & $\mathrm{ns}$ & $*$ \\
Fosfato & $\mathrm{ns}$ & $*$ & $*$ & $\mathrm{~ns}$ & $\mathrm{~ns}$ & $*$ \\
Ponto & Sela Cl & máx ${ }^{2}$ & máx & máx & máx & máx \\
Estacionário & mínimo & 2,59 & 2,26 & 2,43 & 2,44 & 2,71 \\
Torta & 2,63 & -190 & 171,6 & 161,9 \\
Fosfato & - & 190,2 & 145,9 & 168,5 & 171,6 \\
1*, +, ns, respectivamente: significante a 0,05 e 0,10 de probabilidade, e não significante \\
${ }^{2}$ máx = ponto ótimo com máximo
\end{tabular}

Os $\mathrm{R}^{2}$ foram maiores para Brix \% caldo e TPH. Para Brix \%, a resposta ótima é obtida com dose de torta de filtro (T) em torno de 2,59 $\mathrm{t} \mathrm{ha}^{-1}$ e dose de fosfato (F) ao redor de 190,2 $\mathrm{kg} \mathrm{ha}^{-1}$.

Para obtenção dos valores preditos pelas superfícies de respostas mais representativas para Brix\%, as doses de torta $(\mathrm{T})$ e de fosfato $(\mathrm{F})$ podem ser substituídas na equação:

$$
\begin{gathered}
\text { Brix } \% \text { caldo }=19,0032+1,5247 \mathrm{~T}+0,0346 \mathrm{~F}-0,2687 \mathrm{~T}^{2}- \\
-0,00008618 \mathrm{~F}^{2}-0,000696(\mathrm{TF})
\end{gathered}
$$

Já para TPH, o ótimo é com dose de torta de filtro (T) um pouco mais alta, 2,71 t ha-1, e de fosfato $(F)$ um pouco mais baixa, 161,9 $\mathrm{kg} \mathrm{ha}^{-1}$ (Tabela 2). E para obtenção dos valores de $\mathrm{TPH}$, as doses de torta de filtro e de fosfato podem ser substituídas na seguinte equação:

\section{$\mathrm{TPH}=15,8595+4,6440 \mathrm{~T}+0,08414 \mathrm{~F}-0,8590 \mathrm{~T}^{2}-0,000260 \mathrm{~F}^{2}-$ $-0,0000637$ (TF)}

As Figuras 2A e B, mostram as superfícies de resposta construídas para Brix\% caldo e para TPH, respectivamente, com base nos modelos acima descritos.

Os resultados deste trabalho indicam que a torta de filtro pode substituir parte da adubação química fosfatada para se 
A.

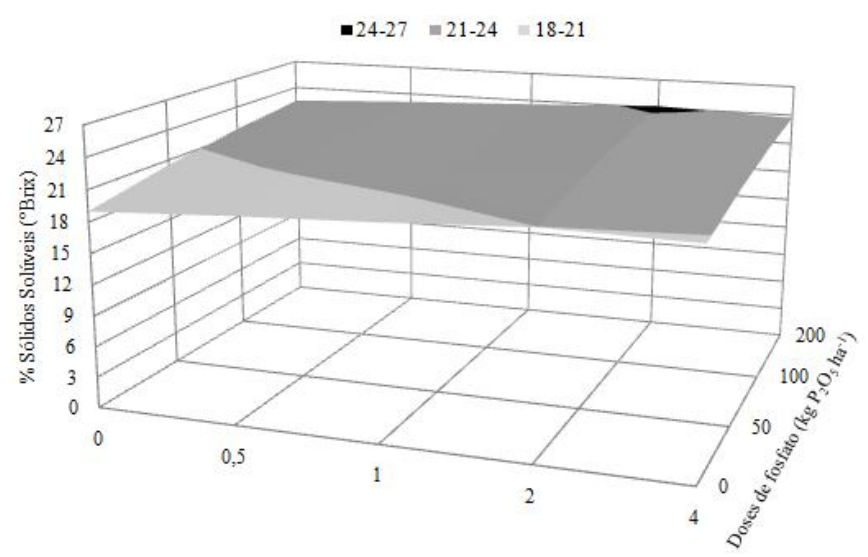

B.

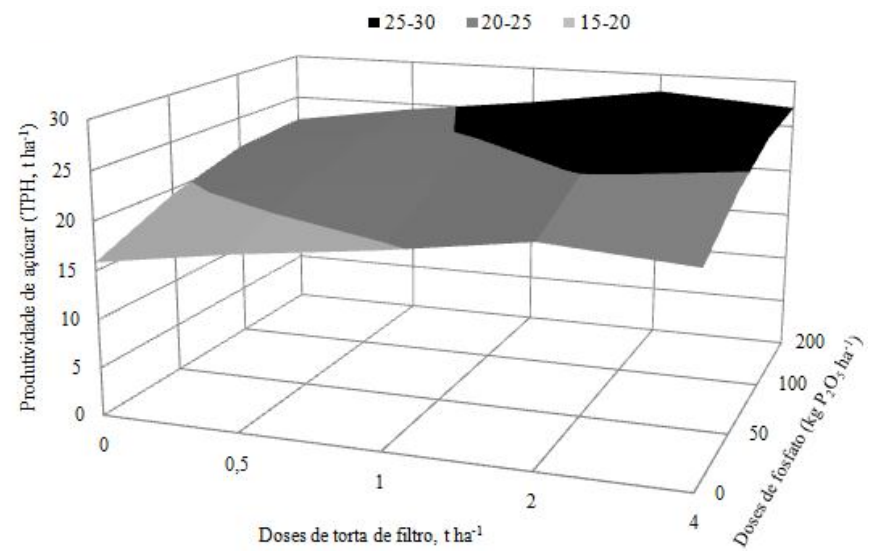

Figura 2. Superfícies de resposta em função de sólidos solúveis (oBrix) (A) e de produtividade de açúcar, em tonelada de pol por hectare (TPH) (B) para doses de torta de filtro versus doses de fosfato

conseguir aumento na produção de sacarose, visto que, baseando-se nas variáveis Brix\% e TPH, em que a superfície de resposta foi mais representativa (maiores $\mathrm{R}^{2}$ ) com efeitos significativos da torta de filtro e do fosfato, a recomendação poderia ser dose de torta de filtro entre 2,6 e $2,7 \mathrm{t} \mathrm{ha}^{-1} \mathrm{e}$ de fosfato entre $160 \mathrm{e} 190 \mathrm{~kg} \mathrm{ha}^{-1}$.

Portanto, os resultados positivos de produtividade de açúcar apontam que a utilização da torta de filtro, associada ao fertilizante fosfatado, pode ser adotada como prática pelos produtores, visando aos ganhos de produtividade, com benefícios do menor uso do fertilizante mineral e melhor utilização do resíduo orgânico da indústria do açúcar. Sugerese, entretanto, que outros estudos sejam realizados a fim de se obter informação da cultura em ciclos consecutivos de colheita, verificando algum efeito residual em diferentes anos agrícolas e tipos de solo e com avaliação do efeito da combinação desses fatores.

\section{CONClusões}

1. O fósforo aplicado no sulco de plantio melhora a qualidade da matéria-prima da cana-de-açúcar, por meio do aumento nos teores de sólidos solúveis, de açúcares redutores totais e de sacarose nos colmos.
2. O fósforo aumenta a produtividade de açúcar.

3. A torta de filtro aplicada no sulco de plantio da cana-deaçúcar tem potencial para substituir parte da adubação química fosfatada visando à melhoria na qualidade e na produtividade de açúcar.

4. A melhor combinação foi torta de filtro na dose entre 2,6 e 2,7 t ha $^{-1}$ associada a 160 e $190 \mathrm{~kg} \mathrm{ha}^{-1}$ de $\mathrm{P}_{2} \mathrm{O}_{5}$, em relação ao teor de sólidos solúveis e produtividade de açúcar.

\section{LITERATURA CITADA}

Albuquerque, G. A. C.; Marinho, M. L. Adubação na região Nordeste. In: Orlando Filho, J. (Coord.). Nutrição e adubação de cana-de-açúcar no Brasil. Piracicaba: IAA/PLANALSUCAR, 1983. p.351-368.

Anjos, I. A.; Andrade, L. A. B.; Garcia, J. C.; Figueiredo, P. A. M.; Carvalho, G. J. Efeitos da adubação orgânica e da época de colheita na qualidade da matéria-prima e nos rendimentos agrícola e de açúcar mascavo artesanal de duas cultivares de cana-de-açúcar (cana-planta). Ciência e Agrotecnologia, v.31, p.59-63, 2007.

Bastos, A. L.; Costa, J. P. V.; Silva, I. F.; Raposo, R. W. C.; Souto, J. S. Influência de doses de fósforo no fluxo difusivo em solos de Alagoas. Revista Brasileira de Engenharia Agrícola e Ambiental, v.12, p.136-142, 2008.

Benedito, D. S.; Prochnow, L. I.; Silverol, A. C.; Toledo, M. C. M. Eficiência agronômica de compostos organominerais obtidos pelo Processo Humifert. Bragantia, v.69, p.191-199, 2010.

Bittencourt, V. C.; Strini, A. C.; Cesarim, L. G.; Souza, S. R. Torta de Filtro enriquecida. Revista Idea News, v.6, p.2-6, 2006.

Elamin, E. A.; Eltilib, M. A.; Elnasikh, M. H.; Ibrahim, S. H.; Elsheikh, M. A.; Babiker, E. E. The influence of phosphorus and potassium fertilization on the quality of sugar of two sugarcane varieties grown on three soil series of Sudan. Journal of Applied Sciences, v.7, p.2345-2350, 2007.

EMBRAPA - Empresa Brasileira de Pesquisa Agropecuária. Centro Nacional de Pesquisa de Solos. Manual de métodos de análise de solos. 2.ed. Rio de Janeiro: EMBRAPA, 1997. 212p.

EMBRAPA - Empresa Brasileira de Pesquisa Agropecuária. Centro Nacional de Pesquisa de Solos. Sistema brasileiro de classificação de solos. Rio de Janeiro: EMBRAPA, 1999. 412p.

Fernandes, A. C. Cálculos na agroindústria da cana-de-açúcar. Piracicaba: STAB, 2003.240p.

Glaz, B.; Powell, G.; Perdomo, R.; Ulloa, M. F. Sugarcane response to phosphorus fertilizer in relation to soil test recommendations on everglades histosols. Agronomy Journal, v.92, p.375-380, 2000.

Korndorfer, G. H.; Anderson, D. L. Use and impact of sugaralcohol residues vinasse and filter cake on sugarcane production in Brazil. Sugar Azucar, v.92, p.26-35, 1997.

Korndörfer, G. H.; Melo, S. P. Fontes de fósforo (fluida ou sólida) na produtividade agrícola e industrial da cana-de-açúcar. Ciência e Agrotecnologia, v.33, p.92-97, 2009. 
Kumar, V.; Verma, K. S. Influence of phosphorus application on soil available phosphorus, yield and juice quality of sugarcane grown on P deficient soil. Indian Sugar, v.39, p.579-587, 1999.

Lima, S. A. A.; Silva, I. F.; Santiago, R. D.; Silva Neto, L. R.; Souza, C.; Cavalcante, F. S. Influência da adubação mineral sobre três cultivares de cana-de-açúcar na microrregião de Guarabira na Paraíba. Agropecuária Técnica, v.27, p.92-99, 2006.

Mahadevaiah, M. S.; Kumar, Y.; Galil, M. S. A.; Suresha, M. S.; Sathish, M. A.; Nagendrappa, G. A simple spectrophotometric determination of phosphate in sugarcane juices, water and detergent samples. E-Journal of Chemistry, v.4, p.467-473, 2007.

Meyer, J. H.; Wood, R. A. The effects of soil fertility and nutrition on sugarcane quality: a review. South African Sugar Technologists Association, v.75, p.242-245, 2001.

Moura, M. V. P. F.; Farias, C. H. de A.; Azevedo, C. A. V. de; Dantas Neto, J.; Azevedo, H. M. de; Pordeus, R. V. Doses de adubação nitrogenada e potássica em cobertura na cultura da cana-de-açúcar, primeira soca, com e sem irrigação. Ciência e Agrotecnologia, v.29, p.753-760, 2005.

Novais, R. F.; Smyth, T. T. Fósforo em solo e planta em condições tropicais. Viçosa: UFV, 1999. 399p.

Nunes Júnior, D. Torta de filtro: De resíduo a produto nobre. Revista Idea News, v.8, p.22-30, 2008.

Penso, J. S. A.; Braga, J. M.; Thiébaut, J. T. L. Avaliação da solubilidade de fosfato de Patos. III - Mistura com torta de filtro e vinhaça. Revista Ceres, v.29, p.516-525, 1982.
Pereira, J. R.; Faria, C. M. B.; Morgado, L. B. Efeito de níveis e do resíduo de fósforo sobre a produtividade da cana-deaçúcar em vertissolo. Pesquisa Agropecuária Brasileira, v.30, p.43-48, 1995.

Raij, B. van; Andrade, J. C.; Cantarella, H.; Quaggio, J. A. Análise química para avaliação da fertilidade de solos tropicais. Campinas: Instituto Agronômico, 2001. 284p.

Raij, B. van; Cantarella, H.; Quaggio, J. A.; Furlani, A. M. C. (ed.) Recomendações de adubação e calagem para o Estado de São Paulo. 2.ed. Campinas: IAC, 1997. 285p. Boletim Técnico, 100.

Rossetto, R; Dias, F. L. F.; Vitti, A. C. Problemas nutricionais dos solos nas novas fronteiras canavieiras. Revista Idea News, v.8, p.78-90, 2008.

Santos, D. H. Adubação da cana-de-açúcar com torta de filtro enriquecida com fosfato solúvel. Presidente Prudente: UNOESTE. 2009. 35p. Dissertação Mestrado

Santos, V. R.; Moura Filho, G.; Albuquerque, A. W.; Costa, J. P. V.; Santos, C. G.; Santos, A. C. I. Crescimento e produtividade agrícola de cana-de-açúcar em diferentes fontes de fósforo. Revista Brasileira de Engenharia Agrícola e Ambiental, v.13, p.389-396, 2009.

Simões Neto, D. E.; Oliveira, A. C.; Freire, F. J.; Freire, M. B. G. S.; Nascimento, C. W. A.; Rocha, A. T. Extração de fósforo em solos cultivados com cana-de-açúcar e suas relações com a capacidade tampão. Revista Brasileira de Engenharia Agrícola e Ambiental, v.13, p.840-848, 2009. 